\title{
VINAGRES DE FOLHAS DE VIDEIRA: ASPECTOS SENSORIAIS
}

\author{
GRAZIELE GUIMARÃES GRANADA * \\ CARLA ROSANE BARBOZA MENDONÇA ** \\ VANESSA PIRES ROSA * \\ RUI CARLOS ZAMBIAZI ****
}

\begin{abstract}
Três diferentes formulações de vinagre de folhas de videira foram elaboradas, mantendo-se a proporção de folhas e água, e variando-se a concentração da sacarose. Realizou-se análise sensorial das formulações, segundo os atributos aparência geral, cor, odor, sabor geral e acidez, além de análise química de acidez titulável. Vinagres comerciais de vinho branco e vinho tinto foram utilizados como padrões. Concluiu-se que somente a formulação com maior teor de sacarose apresentou porcentagem de ácido acético de acordo com os padrões recomendados para tais produtos. Considerando a avaliação sensorial, duas formulações não diferiram significativamente dos vinagres comerciais.
\end{abstract}

\section{INTRODUÇÃO}

A importância do vinagre na alimentação decorre de suas inúmeras formas de utilização, ou seja, como condimento, conferindo sabor ácido aos alimentos em que é adicionado; como conservante, evitando o crescimento de fungos, especialmente em pães e vegetais; sendo bastante útil como agente amaciante de carnes temperadas e legumes em conservas. Além disso, é muito empregado como agente de limpeza, devido sua ação bactericida.

O vinagre pode ser preparado a partir de solução contendo açúcar e nutrientes, que proporcionem fermentação alcoólica seguida de acética.

* Nutricionista, Mestranda em Ciência e Tecnologia Agroindustrial, Universidade Federal de Pelotas (UFPEL).

** Economista Doméstica, Mestre em Ciência e Tecnologia Agroindustrial, UFPEL (e-mail: sidcar@ufpel.tche.br).

*** Aluna do Curso de Química de Alimentos, Faculdade de Ciências Domésticas, UFPEL.

${ }^{* * \star *}$ Professor, Doutor em Food in Nutritional Science, Departamento de Ciência dos Alimentos, Faculdade de Ciências Domésticas, UFPEL. 
Definido como solução diluída de ácido acético, contendo ingredientes solúveis, suas características dependem da matéria-prima, que pode ser obtida de vinho, frutos maduros, material rico em amido, melaço ou caldo de cana, aguardente, álcool, folhas de videira, etc. (OLIVEIRA et al., 1989; KARASZ, BENASSI \& CECCHI, 1998). A industrialização de alimentos pode contribuir de maneira marcante para $o$ incentivo e estabilização da produção agrícola, permitindo aproveitamento de excedentes e gerando novas fontes de renda ao produtor (OLIVEIRA et al., 1987).

Nas pequenas propriedades rurais do Rio Grande do Sul, grande parte da uva é utilizada apenas para consumo de mesa, mesmo sendo este Estado um dos maiores produtores de uva em nível nacional. Desta forma, a utilização das folhas de videira constituí-se em alternativa acessível, para a obtenção artesanal de vinagre, o qual pode ser utilizado na área rural ou até mesmo comercializado, como forma de aumentar a renda familiar nas pequenas propriedades rurais (CONCEIÇÃO \& ZAMBIAZI, 1999).

O presente trabalho teve como objetivo elaborar vinagres a partir de folhas de videira, caracterizá-los sensorialmente e compará-los com vinagres comercias.

\section{MATERIAL E MÉTODOS}

\subsection{MATERIAL}

Para elaboração dos vinagres foram utilizadas folhas de videira (safra 98/99), da região de Pelotas/RS, e sacarose comercial, sendo empregados como padrões vinagres de vinhos branco e tinto de qualidade comercial.

\subsection{PROCESSO DE ELABORAÇÃO DOS VINAGRES}

Foram elaboradas 3 diferentes formulações de vinagre, utilizando-se folhas de videira, açúcar e água nas proporções: 2:1:2(A); 1:1:1(B); e 2:3:2(C), respectivamente. Inicialmente as folhas de videira foram selecionadas, lavadas, escorridas e colocadas nas respectivas caldas, preparadas com água fervida e resfriada até temperatura de $28{ }^{\circ} \mathrm{C}$. Após a mistura em recipientes plásticos, previamente higienizados com água quente e álcool, as folhas foram maceradas manualmente, cobrindo-se os recipientes com tecido de algodão. O processo fermentativo desenvolveu-se ao longo de 60 dias, em ambiente sem incidência direta de luz solar. Ao final da fermentação o produto foi filtrado em tecido de algodão, envasado em embalagens de vidro com capacidade de $500 \mathrm{~mL}$, previamente esterilizadas e fechadas com rolhas de cortiça. Após o envase o produto foi pasteurizado a temperatura de $80 \stackrel{\circ}{\circ}$ em banho-maria, resfriado com água e armazenado a temperatura ambiente. 


\subsection{ANÁLISES}

Os vinagres foram avaliados quanto aos seguintes atributos sensoriais: aparência geral, cor, odor, sabor geral e acidez, por uma equipe de 10 julgadores treinados (ABNT, 1993). Utilizou-se método comparativo, mediante escala não estruturada de $9 \mathrm{~cm}$, tendo como extremos os termos característico e não característico de acordo com a ABNT (1998). As amostras foram apresentadas aos julgadores a temperatura ambiente, utilizando-se como veículo para degustação folhas de alface colocadas em copos descartáveis. Para avaliação do odor foram usados tubos opacos com tampas removíveis e para aparência e cor potes de porcelana, todos codificados com 3 dígitos aleatórios.

Determinou-se acidez titulável das amostras conforme procedimentos indicados nas normas analíticas do Instituto Adolfo Lutz (1985), expressando o resultado em \% de ácido acético.

\subsection{DELINEAMENTO ESTATÍSTICO}

Os resultados foram avaliados pela análise de variância (ANOVA) e os valores que mostraram diferença significativa nas médias foram complementados pelo teste de Duncan, todos ao nível de $5 \%$ de probabilidade, pelo programa Statistica 5.1.

\section{RESULTADOS E DISCUSSÕES}

A Tabela 1 apresenta os resultados obtidos na avaliação sensorial das formulações de vinagre elaboradas e dos vinagres comerciais, além do teor de acidez dos mesmos.

Constatou-se, a partir da determinação de acidez titulável, que o vinagre que apresentou maior percentual de ácido acético foi o vinagre comercial de vinho branco e o de menor concentração em ácido acético o vinagre elaborado segundo as proporções da formulação A. Este resultado foi confirmado pela avaliação sensorial, pois os julgadores detectaram diferenças significativas entre as formulações, não só em termos de acidez, como também, em termos de sabor geral, aparência geral e cor, especialmente, entre o vinagre de vinho branco e a formulação A. Segundo CARVALHO et al. (1998) a qualidade sensorial dos alimentos é cada vez mais importante, e neste sentido, a difusão comercial e a aceitação dos produtos deve embasar-se no conhecimento de suas propriedades sensoriais, as quais contribuem para valorizar e proteger a genuinidade destes produtos. Neste contexto, as técnicas de análise sensorial assumem papel relevante, pois, somente os sentidos humanos, paladar, 


\section{TABELA 1 - CARACTERÍSTICAS SENSORIAIS E ACIDEZ TITULÁVEL DOS VINAGRES ELABORADOS A PARTIR DE FOLHAS DE VIDEIRA E VINAGRES COMERCIAIS}

\begin{tabular}{cccccc}
\hline & \multicolumn{5}{c}{ Vinagres } \\
\cline { 2 - 6 } & 1 & 2 & 3 & 4 & 5 \\
\hline Aparência Geral & $2,5 \mathrm{a}$ & $4,9 \mathrm{ab}$ & $4,9 \mathrm{ab}$ & $5,6 \mathrm{~b}$ & $5,7 \mathrm{~b}$ \\
Cor & $2,7 \mathrm{a}$ & $5,2 \mathrm{ab}$ & $5,2 \mathrm{ab}$ & $6,1 \mathrm{~b}$ & $6,1 \mathrm{~b}$ \\
Odor & $2,8 \mathrm{a}$ & $4,1 \mathrm{a}$ & $4,2 \mathrm{a}$ & $4,2 \mathrm{a}$ & $4,6 \mathrm{a}$ \\
Sabor & $3,6 \mathrm{a}$ & $4,2 \mathrm{ab}$ & $4,6 \mathrm{ab}$ & $6,8 \mathrm{~b}$ & $5,0 \mathrm{ab}$ \\
Acidez & $2,0 \mathrm{a}$ & $5,6 \mathrm{c}$ & $6,0 \mathrm{bc}$ & $7,8 \mathrm{~b}$ & $6,6 \mathrm{bc}$ \\
Acidez Titulável & $1,08 \mathrm{a}$ & $3,17 \mathrm{~b}$ & $4,21 \mathrm{c}$ & $4,58 \mathrm{~d}$ & $3,88 \mathrm{e}$ \\
(\% ácido acético) & & & & & \\
\hline
\end{tabular}

${ }^{1}$ Formulação A (2:1:2; folha de videira:açúcar:água);

${ }^{2}$ Formulação $B(1: 1: 1$; folha de videira: açúcar:água);

${ }^{3}$ Formulação C (2:3:2; folha de videira:açúcar:água);

${ }^{4}$ Vinagre comercial de vinho branco;

${ }^{5}$ Vinagre comercial de vinho tinto.

Letras diferentes na mesma linha evidenciam diferença significativa ao nível de $5 \%$ de probabilidade pelo teste de Duncan $(p<0,05)$.

olfato, visão e tato são capazes de avaliar as características multidimensionais dos alimentos. A análise sensorial dos alimentos deixou de ser atividade secundária e empírica, enquadrando-se na categoria de disciplina científica, capaz de gerar informações precisas e reprodutíveis, sobre as quais recaem importantes decisões acerca da seleção das matérias-primas, das modificações e padronizações de métodos e da otimização de formulações para o desenvolvimento de novos produtos (STONE \& SIDEL, 1993; MORALES, 1999). Considerando os resultados de acidez titulável, as formulações $A$ e $B$ não foram satisfatórias para possibilitar a fermentação do substrato e produzir vinagre com concentração mínima de $4 \%$ de ácido acético, conforme estabelecido pela legislação brasileira (MORETTO et al., 1988). Constatou-se também que o vinagre comercial de vinho tinto apresentou acidez inferior a $4 \%$, estando portanto, abaixo do padrão estabelecido pela legislação.

De acordo com os dados obtidos (Tabela 1) pode-se verificar que, segundo os atributos sensoriais avaliados, as formulações B e C não apresentaram diferenças significativas entre si, ao nível de $5 \%$ de probabilidade. Também não diferiram significativamente dos vinagre comerciais utilizados como padrões, exceto em termos de acidez sensorial entre a formulação B e o vinagre de vinho branco $(p=0,044)$. Observou-se similaridade destas duas formulações com os vinagres comerciais, quanto às características sensoriais. 
$\mathrm{Na}$ avaliação dos atributos, aparência geral, cor, odor, sabor e acidez, as formulações B e C foram consideradas entre as descrições como moderadamente a muito característica a vinagre, tendo recebido valores médios entre 4,1 e 6,0, para todos os atributos sensoriais. Para o mesmo conjunto de atributos a formulação $A$ recebeu dos julgadores valores médios entre 2,0 e 3,6, enquadrando-se nas descrições das fichas de avaliação entre levemente à moderadamente característica a vinagre.

\section{CONCLUSÃO}

O percentual de ácido acético dos vinagres foi diretamente proporcional a acidez sensorial, exceto para o vinagre comercial de vinho tinto.

As formulações B e C não diferiram significativamente entre si, quanto aos atributos sensoriais.

Somente a formulação $\mathrm{C}$ produziu vinagre com percentual de ácido acético suficiente para atender a exigência da legislação brasileira.

Segundo os atributos sensoriais (aparência geral, cor, odor e sabor geral), os vinagres de videira das formulações $B$ e $C$ são similares aos vinagres comerciais de vinho branco e vinho tinto.

\section{Abstract}

Three different vinegar formulations from grapevine leaves were elaborated, maintaining the water-leaves rate and varying the saccharose concentration. Sensory evaluation of the formulations was realized by the characteristics: general appearance, color, odor, general taste and acidity, in addition to chemical analysis of titratable acidity. It was employed commercial vinegars of white wine and red wine, as standards. It was concluded that only the formulation with higher saccharose rate showed acetic acid percentage within the recommended level for this products, however, two of the formulations tested did not differ meaningfully from commercial vinegars.

\section{REFERÊNCIAS BIBLIOGRÁFICAS}

1 ABNT. Métodos de análise sensorial dos alimentos e bebidas, NBR 12994. São Paulo, 1993. 2 p.

2 ABNT. Escalas utilizadas em análise sensorial de alimentos e bebidas, NBR 14141. São Paulo, 1998. $3 \mathrm{p}$. 
CARVALHO, H.H., JONG, E.V., SOUZA, R.B., PEREIRA C.

Desenvolvimento de produtos para fins especiais: dietéticos e baixas calorias. In: CONGRESSO BRASILEIRO DE CIÊNCIA E TECNOLOGIA DE ALIMENTOS, 16., 1998, Rio de Janeiro. Anais... Rio de Janeiro : Sociedade Brasileira de Ciência e Tecnologia de Alimentos, 1998. p. 605-608.

4 CONCEIÇÃO, R, ZAMBIAZI, R.C. Elaboração de vinagre a partir de folhas de videira. Pelotas, 1999. 37 p. Trabalho Científico de Estágio (Graduação em Economia Doméstica), Faculdade de Ciências Domésticas, UFPEL.

5 INSTITUTO ADOLFO LUTZ. Normas analíticas do Instituto Adolfo Lutz. 2.ed. São Paulo, 1985. 371 p.

6 KARASZ, P., BENASSI, M.P., CECCHI, H.M. Caracterização de vinagres brancos de diferentes procedências. In: CONGRESSO BRASILEIRO DE CIÊNCIA E TECNOLOGIA DE ALIMENTOS, 16., 1998. Anais... Rio de Janeiro : Sociedade Brasileira de Ciência e Tecnologia de Alimentos, 1998.

7 MORALES, H.R. Informações sobre Simpósio Iberoamericano de Análise Sensorial. México, 1999. (Informações obtidas via email: kcipolli@bacchus.ital.org.br).

MORETO, E., ALVES, R., CAMPOS, C., ARCHER, R., PRUDÊNCIO, A. Vinhos e vinagres. Florianópolis : Ed. da UFSC, 1988. 167 p.

9 OLIVEIRA, J. et al. Produção de vinagre e álcool à partir de frutos tropicais excedentes de safra. Boletim CEPPA, Curitiba, v. 5, n. 1, p. 33-40, jan./jun. 1987.

10 OLIVEIRA, J. et al. Produção de vinagre de manga (Mangífera indica, L.) e verificação da viabilidade técnica e econômica do projeto. Boletim CEPPA, Curitiba, v. 7, n. 1, p. 45-52, jan./jun. 1989.

11 STONE, H., SIDEL, J.L. Sensory evaluation practices. 2. ed. Florida : Academic Press, 1993. 338 p. 